\title{
EDITORAS DE POESÍA EN LA POSGUERRA ESPAÑOLA: CONCHA LAGOS Y LA RED LITERARIA “ÁGORA" (1955-1973)
}

\author{
María Teresa NaVarrete NaVARrete \\ Universiteit Gent; Universiteit Antwerpen
}

\begin{abstract}
Este artículo estudia la red literaria Ágora que dirigió Concha Lagos a través de la editorial homónima, la revista Cuadernos de Ágora y la tertulia Los Viernes de Ágora. El foco de análisis se sitúa en la editorial de poesía Ágora y en su desarrollo durante la posguerra española. Para ello, la investigación se pregunta, en primera instancia, por el lugar que ocupa la mujer editora en este periodo y por su posición ideológica con respecto al régimen franquista. En segundo lugar, se analiza el sello Ágora y su red de escritores, en la que destacan los grupos de poetas exiliados, de autoras de poesía y de poetas jóvenes.
\end{abstract}

PALABRAS ClAVE: editoras, posguerra española, red literaria Ágora, poesía, Concha Lagos.

Women Editors of Poetry in the Spanish Post-War: Concha Lagos and the "Ágora” Literary Network (1955-1973)

This article studies the Agora literary network, directed by Concha Lagos, through its homonymous publishing house, the magazine Cuadernos de Ágora, and the literary circle "Los viernes de Ágora". The focus of analysis is Ágora, the publishing house that specialized in poetry, and its development during the Spanish post-war period. We tackle, first, the issue of the status of the woman editor in this period and her ideological position with respect to Franco's regime. Secondly, we approach the publishing house Ágora and its network of writers, among which the groups of exiled poets, women poets and young poets stand out.

KEY WORDS: women editors, Spanish post-war, Ágora literary network, poetry, Concha Lagos.

La dificultad marcó la historia de la edición durante el franquismo. La falta de una industria del libro tras el final de la Guerra Civil (1936-1939) y la censura frustraron las posibilidades de publicación de numerosas obras (Carr y Fusi, 1979: 147151; Abellán, 1980: 15-22, 105-136 y 137-154). Esta situación se intensifica en el caso de las mujeres, vetadas del ambiente intelectual a causa del modelo social franquista. Sin embargo, también hubo iniciativas literarias y editoriales que buscaron desligarse de este sistema y propusieron otros modelos. En el caso de la poesía, destaca el proyecto liderado por Concha Lagos (Concepción Gutiérrez Torrero, 1907-2007), directora de la editorial Ágora (Madrid, 1955-1973), de la

Navarrete Navarrete, María Teresa (2019), "Editoras de poesía en la posguerra española: La red literaria 'Ágora' (1955-1973)”, Lectora, 25: 171-186. ISSN: 1136-5781 D.O.I.: 10.1344/Lectora2019.25.10, NavarreteNavarrete.MariaTeresa@UGent.be

Recepció: 15 de desembre de 2018 - Acceptació: 15 d'abril de 2019 
revista Cuadernos de Ágora (1955-1964) y de la tertulia Los Viernes de Ágora (1956-1960).

Este artículo se propone estudiar el origen y el desarrollo del sello de poesía Ágora y la línea de publicación que definió sus acciones dentro del sistema lírico de la posguerra. Para ello, analizaré, en primer lugar, la posición que ocuparon las escritoras en el desarrollo editorial español y la pugna que mantuvieron con el modelo de mujer impuesto por el franquismo. En segundo lugar, examinaré los grupos literarios que el sello Ágora apoyó a través de la publicación y distribución de sus obras. El dibujo de este panorama persigue contemplar una red de escritores que, gracias a la dirección de Lagos, consigue integrar a sectores silenciados por el franquismo, tales como los autores exiliados, extranjeros o perseguidos por cuestiones ideológicas; a las poetas privadas de visibilidad en el circuito literario, y a los jóvenes, aspirantes en busca de una oportunidad editorial.

\section{Los editores de la poesía del medio siglo español}

Al revisar la nómina de los editores de poesía en la España del medio siglo, la aventura de Carlos Barral al frente de Seix Barral aparece en un lugar privilegiado. Su proyecto, gobernado por la promoción del realismo social, triunfa en el panorama lírico. Barral edita dos hitos de la lírica de los años cincuenta: la antología que presenta al grupo considerado canónico en la historia de la poesía del medio siglo, Veinte años de poesía española (1939-1959) (1960), coordinada por Josep Maria Castellet - y su versión corregida y aumentada, Un cuarto de siglo de la poesía española (1939-1964) (1965)—; y la colección Colliure (Barcelona, 1961-1966) integrada en las editoriales Seix Barral y Praxis y también dirigida por Castellet. Barral, el "más solvente editor español" de la posguerra, según lo define Caballero Bonald (2001: 196), consigue que su despacho en Barcelona sea visto por los escritores de aquel momento como una suerte de estudios Paramount (Benet, 1990: 14).

Si bien la editorial Seix Barral participó, desde una posición dominante, en la regeneración del campo de la poesía española después de la Guerra Civil, no fue la única iniciativa que se construyó bajo este mismo afán. Existía la necesidad de "romper un cerco. El estúpido cerco de la 'poesía oficial"' (Celaya, 1976: 22). Muestra de ello son las colecciones Cuadernos de Poesía Norte (1946-1955, San Sebastián), dirigida por Gabriel Celaya y Amparo Gastón (Maraña, 1992); La Isla de los Ratones (Santander, 1949-1986), con Manuel Arce al frente; Neblí (Madrid, 19521955) de Rafael Millán; o El Bardo, fundada por José Batlló (Barcelona, 19641974), entre otras.

Tratándose de poesía, género del que no se hace comercio, como ya advirtió Manuel Vázquez Montalbán (1985), estas colecciones, en su mayoría, no se gestaron siguiendo un plan empresarial. Las motivaciones de los editores se basaban en el deseo de forzar el relevo de la lírica falangista fraguada en el intimismo religioso

172

Lectora, 25 (2019): 171-186. ISSN: 1136-5781 D.O.I.: 10.1344/Lectora2019.25.10 
e individualista (Cano Ballesta, 1994: 121) —revista Escorial (1940-1950) y Garcilaso. Juventud Creadora (1943-1946) - desde una perspectiva estética e ideológica, con la aspiración de recobrar la efervescencia intelectual anterior a la Guerra Civil o con la voluntad de promoción individual o grupal dentro de la sociedad literaria de la posguerra. En algunos casos, estas colecciones provienen de revistas homónimas o cercanas. La Isla de los Ratones, por ejemplo, tiene su origen en la revista La Isla de los Ratones (1948-1955), y los comienzos de la operación editorial de Barral se encuentran ya en las páginas de la revista Laye (1950-1954).

Este relevo implicaba consolidar una reacción ante el franquismo, ante el páramo cultural de los años cuarenta, ante las instituciones culturales controladas por los adeptos al Régimen o ante el olvido de los intelectuales exiliados o asesinados en la guerra. Por ello, los poetas que asumen la dirección de un proyecto editorial lo hacen desde la atalaya de la reivindicación. Un buen ejemplo de este espíritu fue la revista Ínsula (1946-). Sus fundadores, José Luis Cano y Enrique Canito, sufrieron las consecuencias del alzamiento militar desde el comienzo de la Guerra Civil. Cano estuvo en la cárcel de Málaga y Canito, catedrático de Instituto de francés, fue depurado por sus ideas políticas. Las páginas de Ínsula estuvieron a disposición de los jóvenes poetas, sin mostrar preferencia por escuelas o círculos, e intentaron cruzar las fronteras españolas para restablecer el diálogo entre los exiliados y el interior. Hubo otros hitos, en apariencia menos contestatarios por desarrollarse en espacios de factura oficial, pero igualmente críticos. Aquí se sitúa el Aula de Poesía que José Hierro dirigió de 1957 a 1965 en el Ateneo de Madrid, organismo que dependía en aquellas fechas de la Dirección General de la Administración. El Aula de Poesía se convirtió en unos de los salones más transitados por los poetas sociales y llegó a ser definido por Umbral como un "búnker de izquierdas” (2012: 18). En la misma línea, se presenta el premio Adonais de Poesía, "casi la única [...] tarjeta de visita y [...] mérito en todo curriculum poético" (Ramos, 2011: 231) durante la posguerra. La colección y el premio Adonais fueron coordinados por José Luis Cano (1943-63) y Luis Jiménez Martos (1963-2003) y los poemarios ganadores, muchos de ellos adscritos a la poesía social y de ideología antifranquista, los publicaba la editorial Rialp, afín al Opus Dei.

Baste este breve repaso para mostrar la necesidad de ruptura de los intelectuales españoles con el status quo literario configurado a partir de la victoria franquista y también para dejar al descubierto que en la composición de este relato la historia literaria ha concedido a las mujeres un lugar muy escaso. Cabe preguntarse, entonces, por este estrecho margen que conquistaron y reflexionar acerca de la posición real que ocuparon en esta reconversión del panorama cultural español. 


\section{Mujer, literatura y antifranquismo: de aspirantes a promotoras}

La mujer en la posguerra había quedado relegada al ámbito doméstico. Aquellas que lograban superar estos estrechos límites y desarrollaban una identidad como escritoras conseguían, a través de la palabra literaria, no someterse al doble silencio que les imponía la condición de mujeres y súbditas de un sistema dictatorial ( $\mathrm{Pa}$ yeras, 2009). Sin embargo, una vez que acceden a los circuitos literarios, las autoras se enfrentan nuevamente a etiquetas caracterizadoras como las de poetisa o literatura femenina, que confinan su obra a un estadio menor y, por tanto, marginal, caracterizado por el empleo de una retórica menos compleja y una temática relacionada con la intimidad y asociada a los intereses considerados propios de la mujer como, por ejemplo, la maternidad. La ruptura de esta doble definición y la conquista de una identidad de escritora independiente suponen inevitablemente un posicionamiento ideológico que se funda en la defensa de la igualdad y libertad de la mujer, valores en clara oposición con el modelo de sociedad franquista.

La conciencia de las autoras sobre su situación desfavorable en el campo literario de la posguerra se revela en muchas de sus obras y entrevistas. En el ámbito específico de la poesía, por ser el que nos ocupa, no es difícil encontrar composiciones donde se explicita la superación de modelos patriarcales y se reivindica otra identidad para la mujer escritora. Aludo, a modo de ejemplo, a Gloria Fuertes: "Hago versos señores, hago versos / pero no me gusta que me llamen poetisa" (1958: 39); o a Julia Uceda: "Hay que ir demoliendo / poco a poco la sombra que vemos. / Que nos dieron. / Que nos dijeron 'eres”' (1962: 15).

Sin embargo, esta ruptura queda en suspenso cuando no se asimila en el campo literario de la posguerra. Los críticos, en su mayoría hombres, siguen explicando las obras de mujeres según lo que el patriarcado entiende por escritura femenina: "Las críticas que han hecho sobre mi libro [...] no son más que cosas que un hombre dice de una mujer" (24/5/1960: Mss. 22656 $\left.{ }^{154 b}\right),{ }^{1}$ denunciaba Julia Uceda tras publicar su primer poemario, Mariposa en cenizas (1959). A ello se suma la cosificación y sexualización de las autoras en los círculos literarios del franquismo, con independencia de la situación, más o menos ventajosa, dentro del circuito. Medardo Fraile, en sus memorias El cuento de siempre acabar (2009), evoca sus años de subdirector de la revista Cuadernos de Ágora. En el retrato que ofrece de Concha Lagos describe cómo se desarrolló su relación personal y también menciona el físico de la editora. Sin embargo, cuando se refiere a la revista,

\footnotetext{
${ }^{1}$ Carta de Julia Uceda a Concha Lagos. El manuscrito se conserva en el Archivo personal de Concha Lagos (Mss. 22656) depositado en la Biblioteca Nacional de España. Cito de aquí en adelante según la nomenclatura de este Archivo.
}

174

Lectora, 25 (2019): 171-186. ISSN: 1136-5781 D.O.I.: 10.1344/Lectora2019.25.10 
como bien apuntó García Martín (2009), lo hace para destacar la manera en la que creció cuando él se incorporó y su labor de corrector de los versos de la escritora.

La minusvaloración se advierte como una constante del tratamiento que sufre la mujer en la Historia y, al mismo tiempo, es uno de los ejes principales del proceso de exclusión e invisibilidad. Se considera que sus acciones son de tan escaso valor que no merecen ser legitimadas a través del discurso histórico y así se anula su posibilidad de trascendencia. De este modo, aunque La noche que llegué al café Gijón (1977) de Umbral pueda considerarse "un testimonio esencial para configurar la cartografía de las redes culturales, en especial, las literarias, del Madrid de los sesenta" (Ripoll Sintes, 2017: 237), de acuerdo con Concha Lagos, en él las escritoras desaparecen: "pocas mujeres y no muy allá, aparte de 'algunas modelos de piernas largas"” (1977-1978: 163).

La escasez de visibilidad y de rédito crítico respecto a su obra fue detectada por las escritoras de la posguerra. La vía para revertir esta invisibilidad pasaba por intervenir en el campo literario, ya no como creadoras, sino como agentes de una clase movilizada — siguiendo la nomenclatura de Pierre Bourdieu (1988: 97-99)_ , capaces de generar y dirigir estructuras que posibilitaran la publicación, la difusión y la recepción de las obras literarias de las escritoras. Esto significaba desdoblar su presencia en el campo literario de la posguerra y atesorar el control y el poder en parcelas en las que el habitus las posicionaba como eternas candidatas que aspiraban a ser legitimadas (Bourdieu, 2000: 256). En esta estrategia de legitimación y promoción de autores habría que situar el circuito editorial de Ágora. Si bien Lagos estuvo al frente de uno de los proyectos más ambiciosos en el ámbito de la edición de poesía, por fortuna no fue un caso excepcional. ${ }^{2}$

\footnotetext{
${ }^{2}$ Entre las escritoras que lideraron proyectos culturales con el propósito de promover nuevos espacios de intercambio literario durante este tiempo destacan: Trina Mercader, directora de la revista Al-Motamid. Versos y Prosa (1947-1956) y la colección de poesía Itimad (Abrighach, 2018), asociada a la revista del mismo nombre (Larache, 1954-1956); Gloria Fuertes, Adelaida Las Santas y María Dolores de Pablos, fundadoras de Versos con Faldas (Madrid, 1951-1952), la "primera tertulia feminista" que llegó a funcionar como un "grupo cultural feminista" (Las Santas, 1959: 168; 1983: 10); Gloria Fuertes, cofundadora de la revista Arquero de Poesía (1952-1955) junto a Rafael Mir, Antonio Gala y Julio Mariscal; Pino Ojeda, directora de la revista Alisio. Hojas de Poesía (Gran Canaria, 1952-1955); María de los Reyes Fuentes, creadora de la revista ICLA (Sevilla, 1952), directora de Poesía (Sevilla, 1951-1955), programa radiofónico dedicado a la poesía contemporánea, de la revista Ixbiliah (Sevilla, 1953, 1954-1959) y de la colección de poesía homónima (Sevilla, 1957-1964). Hubo más escritoras que colaboraron en la creación de revistas y de editoriales de la posguerra, pero no desde posiciones de liderazgo, por ejemplo, Amparo Gastón en la editorial Cuadernos de Poesía Norte; María Teresa Giralt en Ediciones Arión; Pilar Paz Pasamar en la revista Platero (Cádiz, 1948-1954); Julia Uceda en la revista Rocío (Sevilla,
} 


\section{Concha Lagos al frente del proyecto editorial Ágora}

Concha Lagos conocía el circuito artístico de antes de la Guerra y experimentó el proceso de modernización y de incorporación de la mujer a la vida laboral de los años 20 y 30 (Kirkpatrick, 2003: 36). Frecuentó las tertulias madrileñas del Café de la Granja, del Café Lion, del Café Levante, del Café del Prado, del Café Capitol y de la librería Meléndez. Y, gracias al estudio fotográfico que regentaba en Madrid su marido, Mario Lagos, tuvo contacto con figuras varias del mundo intelectual y artístico tales como José Ortega y Gasset, Luis Cernuda o Imperio Argentina. Pasarán a formar parte de su círculo más cercano Andrés Carranque de los Ríos, el filósofo Juan Aznar y el pintor Anselmo Miguel Nieto. Con la Guerra Civil, este círculo desaparece. Mario y Concha Lagos deciden desmantelar el estudio fotográfico y, debido a la nacionalidad argentina de Mario Lagos, el matrimonio es evacuado en diciembre del 36 desde Alicante a París en el torpedero Tucumán. Carranque de los Ríos muere a causa de un cáncer de estómago al comienzo de la guerra y Aznar y Anselmo Miguel se exilian a Buenos Aires y Chile, respectivamente.

Después de un breve período en París, Mario y Concha Lagos vuelven a España y se refugian en Galicia en una finca propiedad de la familia Lagos, La Seara (Sánchez y Porro, 2015: 15). Vivirían allí hasta 1944, año en el que deciden volver a Madrid para retomar la vida anterior a la guerra. Agustín de Figueroa, marqués de Santo Floro, les ayudó a poner en pie de nuevo el estudio fotográfico y les puso en contacto con la aristocracia española, al igual que hiciera antes del conflicto bélico. Una vez que recuperan la clientela y el negocio comienza a funcionar, Concha Lagos retoma su actividad literaria y vuelve a participar en tertulias como la de la revista Ínsula (Cano, 1986: 75). En estos encuentros, la maestra y articulista Obdulia Guerrero Bueno la anima a publicar sus dos primeras obras: el poemario $E l$ balcón y el libro de cuentos El pantano, escritos en el año de 1937 (Lagos, 19751976: 12; 1977-1978: 181 y 1988: 6 y 31). Con este fin, Guerrero Bueno la pone en contacto con la imprenta madrileña Bachende y con el tipógrafo Rafael Millán (Agulló Cobo, 1958: 304). En 1954, se publican las dos obras pero, al no estar completamente satisfecha con el nivel literario alcanzado, decide lanzarse a "rescatar los ejemplares de las librerías y las manos del distribuidor” (Lagos, 1975-1976: 13).

A raíz de estas visitas a la imprenta, Lagos comienza a interesarse por la revista de poesía que Millán editaba, Ágora. Cuadernos de Poesía (1951-1955) en colaboración con Mercedes Chamorro, Felipe García y Tomás Preciado, así como por la colección de poesía Neblí (1952-1955) que dirigía Rafael Millán junto a Felipe

1955) o María Victoria Atencia en la revista Caracola (Málaga, 1952-1980) y en la colección Cuadernos de Poesía (1955-1961).

176

Lectora, 25 (2019): 171-186. ISSN: 1136-5781 D.O.I.: 10.1344/Lectora2019.25.10 
García Ibáñez y Juan Germán Schröder. ${ }^{3}$ Ágora se publicaba de manera irregular debido a la falta de recursos económicos y Lagos decidió ayudar para favorecer su publicación (Lagos, 1975-1976: 13). Si en un primer momento la escritora se hizo cargo de su financiación, más adelante desempeñó labores de editora en la revista y en la colección Neblí, pero "permaneciendo tras la cortina, sin que mi nombre figurara en ella” (Lagos, 1975-1976: 13). ${ }^{4}$ Sin embargo, después de que Millán le confesara que la revista se trataba de una publicación clandestina, al no estar inscrita en la Dirección de Prensa (Lagos, 1975-1976: 13), ambos deciden comenzar una nueva etapa en $1955 .^{5}$

Lagos se hace cargo de una nueva revista: Cuadernos de Ágora. Su nombre figura como editora, junto con los de Gerardo Diego, José García Nieto, José Hierro y Jorge Campos, quienes componen el Consejo de Redacción, y Emilio González Navarro, director de la publicación. La organización oficial de Cuadernos de Ágora no se correspondía con la situación real de la publicación. De acuerdo con Gómez Gil (1981: 37), Concha Lagos ejercía de directora de la revista. Organizaba las publicaciones, contactaba con los poetas y críticos, componía los números, trataba con la imprenta, se ocupaba de las finanzas y contestaba la correspondencia. José Hierro y Jorge Campos la ayudaban en la gestión de los colaboradores y de los

\footnotetext{
${ }^{3}$ La colección Neblí publicó diecinueve volúmenes bajo la dirección de Rafael Millán (19521955), Felipe García Ibáñez (1952-octubre 1954) y Juan Germán Schröder (1952-enero 1954). Entre ellos, se cuentan: Ramón de Garciasol, Canciones (1952); Ángel Crespo, Quedan señales (1952; segunda edición en 1953); Gerardo Diego, Variaciones (1952); Rafael Millán, Hombre triste (1952); Manuel Pinillos, Tierra de nadie (1952); Antonio Murciano, Navidad (1952); Leopoldo de Luis, Elegía en otoño (1952); Carmen Guasch, Via-crucis (1953); Antonio Fernández Molina, Biografía de Roberto G. (1953); Tomás Preciado, El árbol herido (1953); Manuel Molina, Cambio adelante (1953); Eduardo Alonso, En el viento (1953); Amparo Gastón y Gabriel Celaya, Ciento volando (1953); Julio Mariscal Montes, Corral de muertos (1954); Rafael Montesinos, Cuaderno de las últimas nostalgias (1949-1951) (1954); Lauro Olmo, Del aire (1954); Jean Aristeguieta, Vitral de fábula (1954); Horacio J. De la Cámara, Digo rosa, sueño, canto... (1955); Felipe García Ibáñez, Puente de todos (1955).

${ }^{4}$ Existen datos que corroboran la participación de Concha Lagos en Ágora. Cuadernos de Poesía y en la editorial Neblí. A partir del volumen 34-35 (enero-febrero de 1955) de Ágora. Cuadernos de Poesía aparece su dirección para el envío de la correspondencia. Isabel Paraíso afirma que su incorporación activa en la edición de la revista comienza algunos años antes. Fecha su comienzo en 1952, pero también apunta que su compromiso oficial con ambos proyectos no se consolida hasta 1955 (Paraíso, 2005: 353).

${ }^{5}$ Concha Lagos menciona en sus memorias la clandestinidad de Ágora. Cuadernos de Poesía, pero no hace referencia a la editorial Neblí. Sin embargo, Cecilio Alonso en su estudio sobre la obra de Manuel Molina señala que Neblí se encontraba en la misma situación de ilegalidad que la revista: "Esta colección, que no pasaba la censura, por lo que tenía algo de clandestina en su momento" (Alonso, 1992: 280).
} 
poetas participantes en Cuadernos de Ágora, actividades en las que también intervino Medardo Fraile cuando se incorporó como subdirector en 1958. La presencia de Gerardo Diego y García Nieto se explica por su valor simbólico. No participaron nunca en la composición de la revista, pero la prestigiaron y sus nombres funcionaron como salvaguardas ante la censura. Sin embargo, ninguno de estos autores poseía carné de periodista, título imprescindible para legalizar la publicación. Esto explica que el periodista González Navarro, partidario de Falange Española, figure como director de la publicación. A Lagos le resultaba incómoda esta solución y la justifica del siguiente modo en sus memorias: "Se trató solo de préstamos de un carnet, ya que dicho señor no intervino nunca en nada relacionado con Ágora" (1975-1976: 26). Después de seis años, Lagos consigue sustituir a González Navarro por Jesús Moneo Montoya, titulado en Derecho, Letras y Periodismo y profesor de Derecho Político en el centro de Estudios Universitarios de la Universidad de Madrid.

Junto a Cuadernos de Ágora, Lagos y Millán fundan la editorial Ágora en 1955. El primer volumen, la antología Veinte poetas españoles, se publica en mayo de este mismo año. La antología fue prologada y coordinada por Millán y, según Concha Lagos, Leopoldo de Luis hizo la selección de los veinte poetas, pero prefirió mantenerse en el anonimato para evitar las represalias de los autores no incluidos (Lagos, 1975-1976: 13). Veinte poetas españoles se proponía revertir la mayoría de poetas de estética realista que Francisco Ribes había congregado en su Antología consultada de la joven poesía española (1952), trabajo pionero en definir la poesía de los años cuarenta y cincuenta. Para ello, Veinte poetas españoles ofreció un panorama de los mismos años y, junto a la poesía social, incluyó la neoclásica, la neorromántica, la tremendista, la religiosa, la agónica, la metafísica, la superrealista, la andaluza y la optimista, con el objetivo de legitimar la obra de otros poetas no citados por Ribes, incluidas voces femeninas. A pesar de la poca concreción crítica de las etiquetas utilizadas por Millán para definir la lírica de estos años (Balmaseda Maestu, 1988: 43), desde estas dos antologías ya se atisba la dicotomía entre poesía como comunicación y poesía como conocimiento que polarizó la lírica de los años cincuenta y sesenta en España. Si bien la antología de Millán fue bien recibida por críticos y poetas, también causó cierto revuelo, como ya presagió Leopoldo de Luis, entre los autores ausentes y "empezaron a llover cartas y críticas de los no incluidos" (Lagos, 1975-1976: 13).

Por su parte, Lagos se desmarca de esta antología y aclara en sus memorias que su colaboración fue únicamente económica (1975-1976: 13). En aquel momento, la escritora preparaba un libro sobre su infancia, Al sur del recuerdo, que también saldría en Ágora en 1955. Pero, al margen de estos dos proyectos personales de los directores de la editorial, Ágora se funda con el objetivo de convertirse en un sello especializado en poesía y, así, ese mismo año pone en funcionamiento 
la colección Ágora. Esta serie, compuesta por veintiocho libros impresos en octavo menor, a dos tintas (negra y roja) y decorados con el dibujo de una higuera en la portada, se convierte en el buque insignia de la empresa. En ella publicaron autores significativos de la poesía española contemporánea como Gerardo Diego, Gabriel Celaya, José Hierro, Pablo García Baena o Ángel Crespo y participaron dibujantes como Antonio Povedano, Ricardo Zamorano o Joaquín de la Puente, entre otros, quienes ilustraron estos poemarios con retratos a lápiz de los autores. Elegías del capitán de Luis López Anglada abre esta serie en 1955, que termina con el poemario Con el sudor alzado de Cristina Lacasa en 1964. Algunos libros editados por la colección Ágora fueron distinguidos con galardones como el premio Fastenrath - La red (1955) de José García Nieto-, el premio Antonio Machado - Manera de silencio (1955) de Manuel Alcántara-, el premio Larragoiti - Amazona (1955) de Gerardo Diego-, el premio de la Crítica -Cuanto sé de mí (1957) de José Hierro- o el de poesía Ciudad de Sevilla - El tiempo de nuestros brazos (1958) de Rafael Montesinos. Debido a estas distinciones, La red de García Nieto y Amazona de Diego contaron con una segunda edición en 1956 y, para diferenciarlas de las primeras, se imprimieron en tintas negra y verde.

En paralelo, la editorial Ágora publica otra serie que agrupa, en su mayoría, libros de poesía como Viacrucis (1956) de Gerardo Diego o El buscador (1959) de Elena Andrés, pero también antologías como La rama ingrata (1959) de Rafael Laffón, y novelas como la ya citada Al sur del recuerdo (1955) de Concha Lagos. Esta serie reunió dieciséis títulos que aparecieron entre 1955 y 1968. A diferencia de la colección Ágora de poesía, las portadas de esta serie no se graban con la icónica higuera, también presente en Cuadernos de Ágora, ni guardan un formato regular, aunque predomina el de octava mayor y la impresión a dos tintas que fluctúa entre negra y roja y negra y verde.

Después del cierre de la revista Cuadernos de Ágora en 1964, la editorial homónima solo publica seis títulos. Ante la falta de recursos, Concha Lagos decide asociarse en 1968 con Alfaguara, editorial que Camilo José Cela había fundado cuatro años antes. Alfaguara alberga la colección de poesía Ágora, con el mismo formato y con Lagos como directora. En este período (1968-1973), la colección publica treinta y tres títulos.

Todos los volúmenes de Ágora se imprimieron en el taller de Gráficas Orbe de Madrid y su tirada oscilaba entre los trescientos y quinientos ejemplares por poemario. El precio fue variando según los años. Los primeros volúmenes publicados en 1955 rondaban las veinte pesetas, pero en la década de los sesenta el precio llegó a alcanzar las cuarenta y cinco y, en la etapa de Alfaguara, subió hasta las setenta pesetas.

Como hemos visto, la editorial pasó por distintas fases y sus equipos de dirección evolucionaron a lo largo de los años. De acuerdo a estos cambios, distingo 
cuatro etapas. La primera inicial (de mayo de 1955 a septiembre de 1956), en la que Millán gestiona la editorial y Lagos participa como socia financiera; la segunda etapa de transición (de septiembre de 1956 a noviembre de 1956) caracterizada por un ejercicio compartido de la dirección entre Lagos y Millán; en la tercera etapa (de septiembre de 1956 a enero de 1968), Concha Lagos se convierte en la responsable única y la empresa queda registrada a nombre de Mario Lagos. La escritora, ya directora, se ocupa de todas las actividades derivadas de la editorial, como contratos, pagos de la imprenta, edición, distribución o correspondencia. Esta es la fase en la que el sello alcanza su mayor volumen de actividad y reconocimiento. Se editan veintisiete poemarios, se crea el Premio de Poesía Ágora (1962-1963) y los libros de la editorial son distinguidos por el Instituto Nacional del Libro Español entre los cincuenta mejor editados del año 1956. Después de esta etapa de esplendor, Ágora, como ya he mencionado, pasa a ser una colección de la editorial Alfaguara y Lagos ejerce como editora en estos años (1968-1973), pero la serie, al igual que otras colecciones, se debilita hasta desaparecer cuando Camilo José Cela se distancia de Alfaguara en 1972 (Pedrazuela, 2010: 340-341).

\section{La edición como vía de restitución de la cultura española: la red literaria Ágora}

Concha Lagos, cuando hace recuento de los objetivos de Ágora en sus memorias, explica que "en aquellos años tan difíciles" trataron de "airear las voces silenciadas por la censura y la de los exiliados" y de "destacar las voces femeninas" y los "poetas jóvenes" (1976-1977: 83).

Tal como demuestran los números de Cuadernos de Ágora dedicados a Andrés Carranque de los Ríos, Federico García Lorca, Miguel Hernández o Rafael Alberti, Concha Lagos desafía a través de su proyecto cultural los límites de la censura española durante la posguerra. No titubeó en publicar poemarios críticos con el régimen franquista; de autores que habían sido encarcelados como José Hierro; o de afiliados al Partido Comunista como Gabriel Celaya o Ángel Crespo. Lagos tampoco renunció a publicar a autores exiliados como Ernestina de Champourcín o Manuel Durán, o a los emigrantes que decidieron abandonar España voluntariamente en busca de mejores oportunidades laborales en el ámbito universitario estadounidense como Julia Uceda, Alfredo Gómez Gil o Isabel Paraíso. La nómina de poetas y obras que Lagos consiguió sacar en la colección y en la revista fueron el resultado de la lucha que mantuvo con la censura "a cuerpo limpio" (Lagos, 1975-1976: 28), como le gustaba decir. La escritora, cuando la censura detenía sus publicaciones - por ejemplo, los números de Cuadernos de Ágora dedicados a Miguel Hernández, Federico García Lorca y Rafael Alberti lo estuvieron por varios meses-, acudía tantas veces como fueran necesarias a la Dirección General de Prensa para entrevistarse con el director (Medrano, 1974: s.p.) y romper el limbo 
al que el silencio administrativo confinaba muchas obras (Abellán, 1980: 149). Pero, en otras ocasiones, Lagos no conseguía vencer las restricciones de la censura y las editoriales de fuera de España se contemplaban como la única vía de publicación posible. De acuerdo con Estrella Correcher Juliá (2014: 148), los fuertes vínculos entre Ágora y la revista venezolana Lírica Hispana permitieron que poetas como Amparo Gastón, Gloria Fuertes o Gabriel Celaya vieran publicadas sus obras A flor de labio (1958), Todo asusta (1958) y El corazón en su sitio (1959), respectivamente.

Ágora también intentó acercar la literatura extranjera a la sociedad española. Por un lado, Lagos invitaba a autores latinoamericanos a escribir en Cuadernos de Ágora y logró que escritores como Nicolás Guillén, Ciro Alegría o Dulce María Loynaz participaran en sus páginas. Además, Lagos solía enviar Cuadernos de Ágora a otras redacciones de revistas latinoamericanas de creación poética como la ya mencionada Lírica Hispana, la mexicana Noéma o la paraguaya Cuenco, para que dieran cuenta de las noticias literarias de España. Estos envíos fraguaron un intercambio de revistas y libros que contribuyó a que la "Crítica de libros" de Cuadernos de Ágora también incluyera reseñas de las obras publicadas en Latinoamérica. El sello Ágora aprovechó el contacto con los autores americanos que colaboraban en Cuadernos de Ágora para incorporarlos a su catálogo (Correcher Juliá, 2014: 142). Formaron parte de esta nómina Concha Zardoya, Enrique Ángel Renzis, Carlos Martín Fajardo y Jean Aristeguieta a través de un estudio de Hugo Emilio Pedemonte. Sin embargo, el miedo a la censura no favoreció que estos intercambios se materializaran plenamente. Por ejemplo, en las cartas que recibe Lagos relativas a la publicación de los cuentos de Ciro Alegría en Cuadernos de Ágora, las potenciales supresiones de los censores condicionan cada una de las decisiones editoriales (Varona, 20/12/1961: Mss. 22656 274; 31/7/1962: Mss. 22656 ${ }^{275}$ ).

Por otro lado, Lagos contó con traductores como José María Valverde —catedrático de Estética de la Universidad de Barcelona que se exilia a Canadá por solidaridad política con Enrique Tierno Galván, José Luis López Aranguren y Agustín García Calvo-, quien se encargó de la obra de Rainer Maria Rilke en el volumen Cincuenta poesías (1957); el narrador Jorge Ferrer-Vidal Turull, traductor de Dylan Thomas para el volumen Poemas escogidos (1958); o Gabriel Amiama - uno de los niños de la guerra enviado a Moscú y retornado- y Antonio Gómez Alfaro - periodista y editor de la revista Alfoz- quienes tradujeron del ruso la obra de Boris Pasternak Antología de urgencia (1959).

Una de las principales batallas que Lagos libró desde su editorial fue la difusión de la poesía escrita por mujeres. Si repasamos la lista de escritores de Ágora, aparecen autoras como Ernestina de Champourcín, Pilar Paz Pasamar, Cristina Lacasa, María Teresa Burillo, Concha Zardoya, Elena Andrés, Julia Uceda, Ana María Fagundo, Sagrario Torres, Ágata Guzmán, Ángeles Escriva, Isabel Paraíso, 
entre otras. Sin embargo, según la correspondencia que Lagos mantiene con las escritoras, pudieron ser más. Algunos proyectos editoriales se frustraron debido a las dificultades que encontraban para desarrollar sus carreras literarias. Dora Varona, por ejemplo, confesaba los obstáculos que padecía para conciliar sus responsabilidades familiares con sus aspiraciones artísticas: "Creo que es muy difícil poder ser buena poeta y una mujer normal, con un hogar feliz" (30/12/1965: Mss $/ 22656^{280}$ ).

En el asesoramiento editorial que Lagos ejerció con las poetas, destaca su perseverancia. Comprendía las causas de las negativas de las autoras y, por ello, no cesaba en proponerles oportunidades de publicación tal como demuestra la correspondencia mantenida con Amparo Gastón (s.f.: Mss. 22652 ${ }^{93 \mathrm{bis}}$ ) y Marina Romero (s.f.: Mss. 22652 $225-226$ ). En esta misma línea, Lagos decidió dedicar una sección a las poetas en el apartado "Crítica de libros" de la revista Cuadernos de Ágora. Julia Uceda se encargó de este espacio, después de que otros colaboradores se mostraran poco receptivos: “A Julia Uceda le reservé la poesía femenina, ya que J. Martos le ponía mala cara y, para esquivarla, decía que había perdido los libros de las poetisas" (1977-1978: 156). En esta sección, Uceda reseñó obras de Pilar Valderrama, Chona Madera, María de los Reyes Fuentes o Cristina Lacaci. Las cartas que intercambiaron Lagos y Uceda para confeccionar esta sección resultan las más fructíferas para comprender la posición feminista mantenida desde el proyecto Ágora (21/9/1961: Mss. 22656 ${ }^{159}$; 20/12/1961: Mss. 22656 ${ }^{163}$; 17/2/1963: Mss. $\left.22656^{171}\right)$. Un buen resumen de estas discusiones se encuentra en la reseña sobre la poesía de María Eugenia Rincón que Uceda publicó en Cuadernos de Ágora:

Cuando una poeta adquiere determinada altura intelectual [...] es pueril e insuficiente enfocar el fenómeno poético [...] exclusivamente desde el punto de vista de su feminidad. Con ello algunos críticos nos sorprenden más que con el talento que le reconocíamos, con su visión masculina de las cosas. Y esta visión, tan parcial y pequeñita - tan peyorativa, consciente e inconscientemente-, de lo que es en realidad muy complejo, no significa otra cosa que caer en una visión poco clara [...]. La sensibilidad poética ni puede definirse según determinados patrones ni es exclusiva de ninguno de los dos géneros. (Uceda, 1963: 43)

La editorial Ágora se caracterizó por su carácter aperturista. Combinó en su colección de poesía Ágora la publicación de libros de autores consolidados como, por ejemplo, Adriano del Valle, quien publicó su último libro en vida, Égloga de Gabriel Miró y Fábula del Peñón de Ifach (1957), en esta colección, con la de aquellos que se encontraban en estadios intermedios de sus carreras tales como Pablo García Baena, que después de sacar Óleo (1958) en Ágora decidió dejar de publicar durante una década, y también con la de los escritores que veían impresos sus 
poemas por primera vez como fue el caso de Manuel Alcántara, Manera de silencio (1955), o José María Requena, finalista del Adonais por La sangre por las cosas (1956). A los más jóvenes, Concha Lagos los ayudó además a publicitar sus obras en revistas especializadas y a distribuirlas en las librerías. Para muchos autores, esta editorial supuso el salto desde los centros provinciales de cultura hasta el circuito lírico de la capital.

Como se aprecia, la nómina de los poetas publicados en Ágora es diversa y cuenta con representantes de distintas tendencias. Juan Bernier, Ricardo Molina y Pablo García Baena del grupo Cántico (Córdoba, 1947-49 y 1954-57), Gabriel Celaya, José Hierro o Ramón de Garciasol como representantes de la poesía comprometida, o Leopoldo de Luis y Manuel Mantero afines a la corriente existencialista. Esta diversidad contrasta con el programa estético de la Escuela de Barcelona fundado en el social realismo y que, a partir de la antología Veinte años de poesía española (1939-1959), marca la lírica del medio siglo. En cierta forma, los poemarios publicados por Ágora se distancian de esta tendencia e incluso aquellas propuestas más críticas con el Franquismo como, por ejemplo, Sin mucha esperanza (1966) de Julia Uceda, que sufrió los cortes de la censura, apuestan por una línea más simbolista. Esta reacción al social realismo también se aprecia en las antologías que Ágora apoyó, como fue el caso de Nuevos poetas españoles (1961) de Luis Jiménez Martos que venía a recopilar la poesía excluida por Castellet (Ortiz, 1981: 24; Balmaseda Maestu, 1988: 46).

Si bien Ágora publicó autores cercanos al Régimen y más integrados en los circuitos oficiales como José María Pemán o José García Nieto, se advierte que los objetivos de esta editorial persiguen un mismo fin: contribuir a la incorporación de grupos de escritores excluidos por el sistema literario franquista. Esta asociación con los autores invisibilizados y marginados por cuestiones ideológicas, de género o de falta de trayectoria $y$, por tanto, de prestigio dentro del campo contemporáneo, favoreció que la editorial Ágora trazara una red literaria alternativa, disidente y heterodoxa que se extendió desde Madrid a las capitales de provincia españolas, a los centros culturales latinoamericanos y a los grupos de exiliados en Europa y América. En la conjunción de estos grupos de escritores en torno a un mismo epicentro reside el éxito y la victoria de esta editorial frente al silencio y la censura que el franquismo impuso desde su política cultural.

\section{Conclusión}

La editorial Ágora y la red de escritores que se congregó en torno a ella ejemplifican el crecimiento de un sistema literario que se desmarca de los cauces culturales del franquismo. El estudio de editoriales o acciones literarias dirigidas por agentes culturales que, como Concha Lagos, parten de una posición poco privilegiada dentro del sistema cultural oficial del franquismo, debido a condicionantes ideológicos 
y de género, revelan el origen y los esfuerzos individuales y colectivos que los escritores de la posguerra pusieron en marcha para conseguir que un pensamiento crítico y en oposición al Régimen progresara. Para explicar esta evolución, los estudios han puesto su foco mayoritariamente en las acciones capitaneadas por editores o escritores y han dejado al margen de esta progresión las lideradas por mujeres; el análisis de la editorial Ágora revela la necesidad de contemplarlas a la hora de completar el mosaico de la lucha cultural jugada en la posguerra. No hay que olvidar que fueron las escritoras, las que, desde la posición más debilitada, libraron una doble rebelión ante la sociedad franquista y el sistema literario patriarcal.

\section{REFERENCIAS BIBLIOGRÁFICAS}

Abellán, Manuel (1980), Censura y creación literaria en España (1939-1976), Barcelona, Ediciones Península.

Abrighach, Mohamed (2018), “Colección Itimad (Tetuán, 1954-1956) [Semblanza]", portal Editores y Editoriales Iberoamericanos (siglos XIX-XXI), EDI-RED, Alicante, Biblioteca Virtual Miguel de Cervantes. $<$ http://www.cervantesvirtual.com/obra/coleccion-itimad-tetuan-1954-1956semblanza-931432/>

Agulló Cobo, Mercedes (1958), “Escritores contemporáneos: Concha Lagos”, El Libro Español: Revista Mensual del Instituto Nacional del Libro Español, 6: 303306.

Alonso, Cecilio (1992), “Introducción”, en Manuel Molina, Versos escogidos, Alicante, Instituto de Estudios Juan Gil-Albert: 11-24.

Balmaseda Maestu, Enrique (1988), "La poesía española de posguerra a través de sus antologías”, Cuadernos de Investigación Filológica, 14: 41-55.

Benet, Juan (1990), “El efecto Barral”, Revista de Occidente, 110-114: 11-16.

Bourdieu, Pierre (1988), La distinción. Criterio y bases sociales del gusto, María del Carmen Ruiz de Elvira (trad.), Madrid, Taurus.

-(2000), Esquisse d'une théorie de la practique, París, Seuil/Points.

Caballero Bonald, José Manuel (2001), La costumbre de vivir, Madrid, Alfaguara.

Cano, José Luis (1986), Los cuadernos de Velintonia. Conversaciones con Vicente Aleixandre, Barcelona, Seix Barral.

Cano Ballesta, Juan (1994), Las estrategias de la imaginación. Utopías literarias y retórica política bajo el franquismo, Madrid, Siglo XXI.

Carr, Raymond y Juan Pablo Fusi (1979), España, de la dictadura a la democracia, Barcelona, Planeta.

184

Lectora, 25 (2019): 171-186. ISSN: 1136-5781 D.O.I.: 10.1344/Lectora2019.25.10 
Castellet, Josep Maria (1960), Veinte años de poesía española (1939-1959), Barcelona, Seix Barral.

-(1966), Un cuarto de siglo de poesía española (1939-1965), Barcelona, Seix Barral.

Celaya, Gabriel (1976), Itinerario poético, Madrid, Cátedra.

Correcher Juliá, Estrella (2014), "La revista Cuadernos de Ágora y sus relaciones con Latinoamérica”, Mitologías Hoy, 9: 140-156.

Fraile, Medardo (2009), El cuento de siempre acabar, Valencia, Pre-Textos.

Fuertes, Gloria (1958), Todo asusta, Caracas, Lírica Hispana.

García Martín, José Luis (2009), "Mi vida y otros cuentos”, La Nueva España, 9/8/2018. <https://www.Ine.es/cultura/2009/06/05/vida-cuentos/763785.html>

Gastón, Amparo (s.f.), Carta a Concha Lagos, Madrid, Biblioteca Nacional de España: Mss. 22656 ${ }^{93 \mathrm{bis}}$.

Gómez Gil, Alfredo (1981), Concha Lagos bajo el dominio de la literatura comparada, Alicante, Instituto de Estudios Alicantinos.

Kirkpatrick, Susan (2003), Mujer, modernismo y vanguardia en España (18981931), Madrid, Cátedra.

Lagos, Concha (1975-1976), La Madeja I, Madrid, Biblioteca Nacional de España.

-(1977-1978), La Madeja II, Madrid, Biblioteca Nacional de España.

-(1988), Prolongada en el tiempo, Madrid, Biblioteca Nacional de España.

Las Santas, Adelaida (1959), Poetas de café, Madrid, Editorial Clásica Moderna.

-(1983), Versos con faldas. (Breve historia de una tertulia intelectual femenina), Madrid, Aguacantos.

Maraña, Félix (1992), “Celaya, introductor de poetas”, Zurgai, diciembre: 34-37.

Medrano, Susana (1974), La poesía de Concha Lagos. La trilogía fundamental, Madrid, Instituto de Cultura Hispánica.

Ortiz, Fernando (1981), Introducción a la poesía andaluza contemporánea, Sevilla, Calle del Aire.

Paraíso, Isabel (2005), “Cuadernos de Ágora (1956-1964)”, Revistas literarias españolas del siglo XX (1919-1975), José Manuel Ramos Ortega y José María Barrera López (eds.), Madrid, Ollero y Ramos Editores: 353-398.

Payeras Grau, María (2009), Espejos de palabra. La voz secreta de la mujer en la poesía española de posguerra (1939-1959), Madrid, UNED.

Pedrazuela Fuentes, Mario (2010), Alonso Zamora Vicente: Vida y filología, Alicante, Publicaciones de la Universidad de Alicante.

Ramos Ortega, Manuel J. (2011), "El cauce de Adonais: El caso de Ángel García López”, La poesía de Ángel García López, José Jurado Morales (ed.), Madrid, Visor: 217-236. 
Ribes, Francisco (1952), Antología consultada de la joven poesía española, Valencia, Mares.

Ripoll Sintes, Blanca (2017), "El espacio de lo posible: Las tertulias literarias en La noche que yo llegué al Café Gijón de Francisco Umbral”, Actio Nova. Revista de Teoría de la Literatura y Literatura Comparada, 1: 221-240.

Romero, Marina (s.f.), Cartas a Concha Lagos, Madrid, Biblioteca Nacional de España: Mss. 22656 225-226.

Sánchez Dueñas, Blas y María José Porro Herrera (2015), Concha Lagos. Agente cultural: Los Cuadernos de Ágora, Madrid, Universidad Nacional de Educación a Distancia.

Uceda, Julia (1960), Carta a Concha Lagos, Madrid, Biblioteca Nacional de España: Mss. 22656 ${ }^{154 b}$. [24/5/1960]

-(1961), Carta a Concha Lagos, Madrid, Biblioteca Nacional de España: Mss. $22656^{159}$. [21/9/1961]

-(1961), Carta a Concha Lagos, Madrid, Biblioteca Nacional de España: Mss. $22656^{163}$. [20/12/1961]

-(1963), Carta a Concha Lagos, Madrid, Biblioteca Nacional de España: Mss. $22656^{171}$. [17/2/1963]

Umbral, Francisco (2012), La noche que llegué al Café Gijón, Barcelona, Austral.

Varona, Dora (1961), Carta a Concha Lagos, Madrid, Biblioteca Nacional de España: Mss. 22656 ${ }^{274}$. [20/12/1961]

-(1962), Carta a Concha Lagos, Madrid, Biblioteca Nacional de España: Mss. $22656^{275}$. [31/7/1962]

-(1963), “Tierra secreta de María Eugenia Rincón”, Cuadernos de Ágora, 75-78: 42-46.

-(1965), Carta a Concha Lagos, Madrid, Biblioteca Nacional de España: Mss. $22656^{280}$. [30/12/1965]

Vázquez Montalbán, Manuel (1985), “Sobre 'los novísimos’ y sus postrimerías”, El País, 4/9/2018.

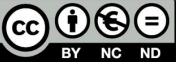

